\title{
Synthesis and antibacterial activity of modified $\varepsilon$-polylysine
}

\author{
Qunshan Cai ${ }^{1}$, Hongwei Zhu ${ }^{1}$, Keli Zhong ${ }^{1, *}$ \\ ${ }^{1}$ College of Chemistry and Materials Engineering, College of Food Science and Technology, Bohai University; Food Safety Key Lab of \\ Liaoning Province; National \& Local Joint Engineering Research Center of Storage, Processing and Safety Control Technology for Fresh \\ Agricultural and Aquatic Products; Bohai University, Jinzhou, 121013, China.
}

\begin{abstract}
In this paper, Ugi reaction was used to synthesize the modified polylysine (M- $\varepsilon-P L)$ in two steps, and OD value was measured by ultraviolet spectrophotometer to determine the inhibitory rate of M- $\varepsilon$-PL in different concentrations of Escherichia coli and Staphylococcus aureus. The results showed that the antibacterial effect was better with the increase of concentration of M- $\varepsilon$-PL. Among them, $20 \mathrm{mg} / \mathrm{mL} \mathrm{M- \varepsilon -}$ PL had better bacteriostatic effect on E. coli and S. aureus. The antibacterial rate was $70 \%$ and $44 \%$.
\end{abstract}

\section{Introduction}

The $\varepsilon$-polylysine is a homopolymer composed of the essential amino acid, which is connected by the hydroxyl group and the amino group to form an amide bond. It is a natural product with antiseptic function and also a nutritive biological preservative [1]. Because of its good antibacterial activity, it is often used in bacteriostatic experiments against various kinds of bacteria. Liu et al studied the effects of $\varepsilon$-polylysine on the bacterial community. The results show that $\varepsilon$-polylysine can inhibit the growth of Pseudomonas, Shewanella and Acinetobacter [2]. The $\varepsilon$-polylysine has good antibacterial effect and broad-spectrum antibacterial property, but it also has some disadvantages such as short release time [3, 4]. Therefore, we modified it and synthesized M- $\varepsilon-\mathrm{PL}$ by Ugi reaction using N $\alpha-\mathrm{Boc}-\mathrm{L}-$ lysine as the substrate. The reaction condition is mild, the efficiency is high, the atom economy is good, is widely used in the synthetic chemistry, the pharmaceutical and the life science domain. M-E-PL is an amphiphilic polymer containing hydrophilic amino and hydrophobic subunits, which has better bacteriostatic effect than general bacteriostatic agents, and has a good application prospect in food preservation.

\section{Materials and methods}

\subsection{Synthesis of $M-\varepsilon-P L$}

The required amount of tertiary butyl nitrile $(0.18 \mathrm{~g}, 2.2$ mmol) was added to a suspension of $\mathrm{MeOH}(2 \mathrm{~mL})$ containing $\mathrm{N} \alpha$-Boc-L-lysine $(0.24 \mathrm{~g}, 1.0 \mathrm{mmol})$ and benzaldehyde $(0.23 \mathrm{~g}, 2.2 \mathrm{mmol})$ and then under the magnetic stirrer for $95 \mathrm{~h}$ at $25^{\circ} \mathrm{C}$. The volatile matter was removed by vacuum, and the residue was dissolved in $2 \mathrm{~mL} \mathrm{CH} 2 \mathrm{Cl} 2$, the solution was precipitated several times in petroleum ether and dried under vacuum at room temperature to give the polypeptide $\mathrm{P} 1$ as a white solid.

Trifluoroacetic acid $(1.2 \mathrm{~mL})$ was slowly added to a solution of $\mathbf{P 1}(1.0 \mathrm{~g})$ in dry $\mathrm{CH}_{2} \mathrm{Cl}_{2}(6.0 \mathrm{~mL})$ at $0{ }^{\circ} \mathrm{C}$ and then under the magnetic stirrer for $3 \mathrm{~h}$ at $25{ }^{\circ} \mathrm{C}$. The polymer solution was concentrated and precipitated in petroleum ether. White solid (M- $\varepsilon-\mathbf{P L}, 0.981 \mathrm{~g}$ ) was obtained [5]. The synthetic route of $\mathbf{M}-\varepsilon-\mathbf{P L}$ is shown in Fig.1.

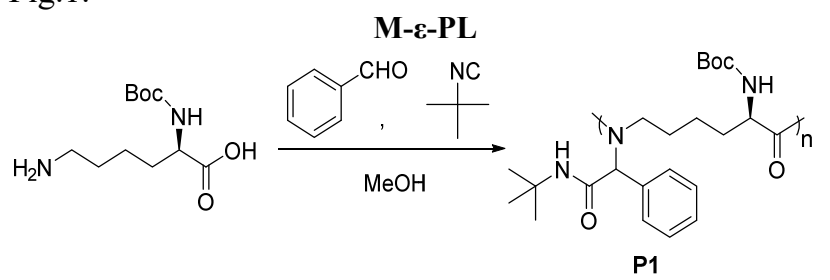<smiles>CN(CCCCC(N)C(=O)OCC(C)(C)C)C(C(=O)NC(C)(C)C)c1ccccc1</smiles>

Fig.1 The synthesis of M- $\varepsilon-\mathbf{P L}$ compounds

\subsection{The antibacterial experiments of $M-\varepsilon-P L$ to Escherichia coli and Staphylococcus aureus}

Firstly, the OD value at $600 \mathrm{~nm}$ was measured by ultraviolet spectrophotometer. When the OD value was 1.0 , different concentrations of M- $\varepsilon-P L$ were added, and the OD value was tested again after $24 \mathrm{~h}$. The standard OD difference from the addition of M- $\varepsilon-P L$ was used to calculate the percent inhibition of E. coli and S. aureus against different concentrations [6].

On the basis of the above inhibition efficiency test, the inhibition efficiency of $20 \mathrm{mg} / \mathrm{mL} \mathrm{M}-\varepsilon-\mathrm{PL}$ was tested again by using the dilution plate method, and the above 5 $\mathrm{mL}$ bacterial solution was diluted to $1 \mathrm{~mL}$ with $20 \mathrm{~mL}$. Then, 10 microliters are moved to $1 \mathrm{~mL}$ with a pipette

* Corresponding author: zhongkeli2000@bhu.edu.cn (K. Zhong) 
and diluted to $5 \mathrm{~mL}$ and from $5 \mathrm{~mL}$ to 50 microliters for dilution of E. coli and S. aureus [7].

\subsection{SEM characterization of Pseudomonas fluorescens by $M-\varepsilon-P L$}

Take a certain amount of Pseudomonas fluorescent and sterile Phosphate Buffer solution (PBS) buffer, adjust the concentration to OD600 $=0.5$, then take $20 \mathrm{~mL}$ PBS suspension, one group is a blank control group, and the other group is treated with $0.2 \% \mathrm{M}-\varepsilon-\mathrm{PL}$, shake at $30^{\circ} \mathrm{C}$ for $12 \mathrm{~h}$ and centrifuge at $3000 \mathrm{r} / \mathrm{min}$ for $10 \mathrm{~min}$. After centrifugation twice, the supernatant was decanted, $2 \mathrm{~mL}$ of cooled $2.5 \%$ glutaraldehyde was mixed with the bacteria, fixed for $2 \mathrm{~h}$, and then rinsed with sterile water 2-3 times. After dehydration with absolute ethanol, it was dried at $37^{\circ} \mathrm{C}$ for $72 \mathrm{~h}$, and then observed with a scanning electron microscope [8].

\section{Results and discussion}

\subsection{Antibacterial effect of $M-\varepsilon-P L$ on $E$. coli and S. aureus}
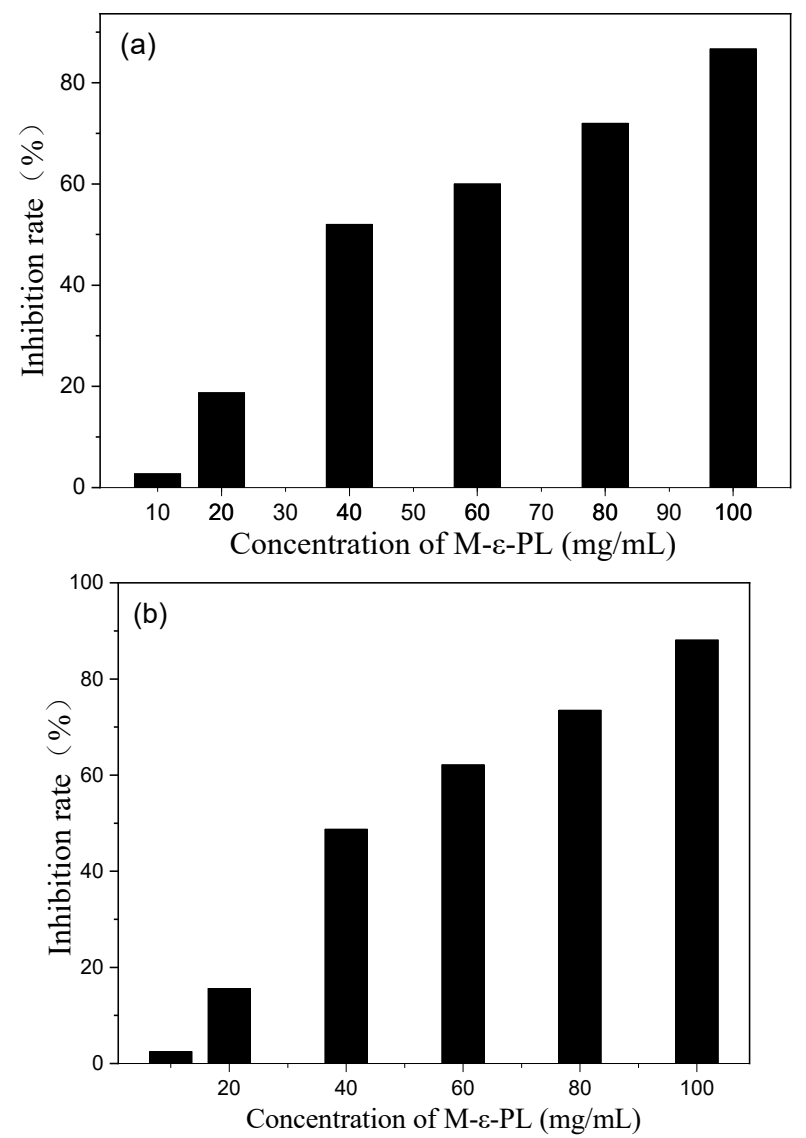

Fig. 2. Percentage inhibition of (a) E. coli and (b) S. aureus by M-E-PL

As shown in Figure 2, the inhibitory percentage of M- $-\varepsilon-$ $\mathrm{PL}$ on E.coli and $\mathrm{S}$. aureus also increased with the increase of concentration of M- $\varepsilon-\mathrm{PL}$. When the concentration of M- $\varepsilon-\mathrm{PL}$ is $100 \mathrm{mg} / \mathrm{ml}$, the sterilization rates of E. coli and S. aureus are both above $80 \%$.
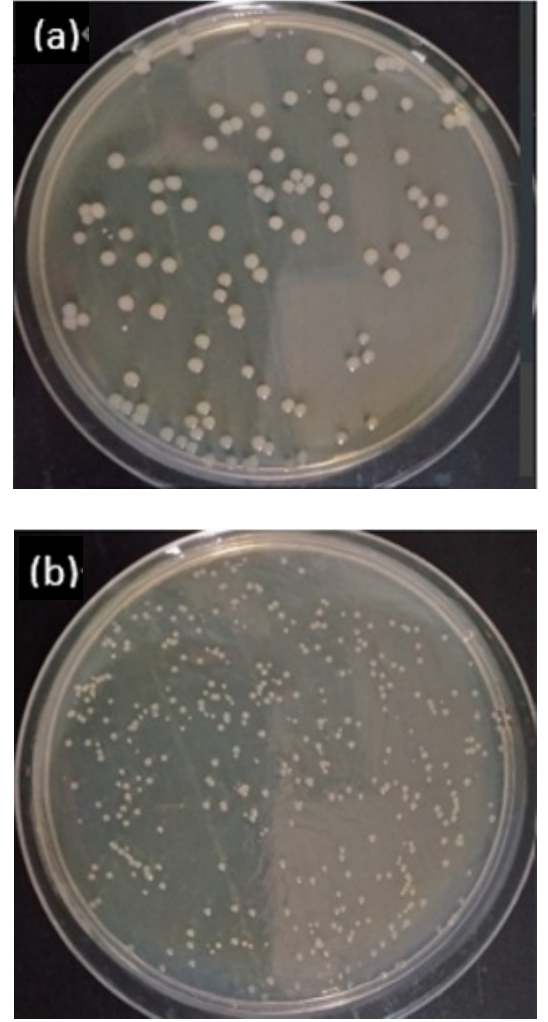

Fig. 3. The number of colonies treated E. coli by (a) M-\&-PL, (b) the blank control
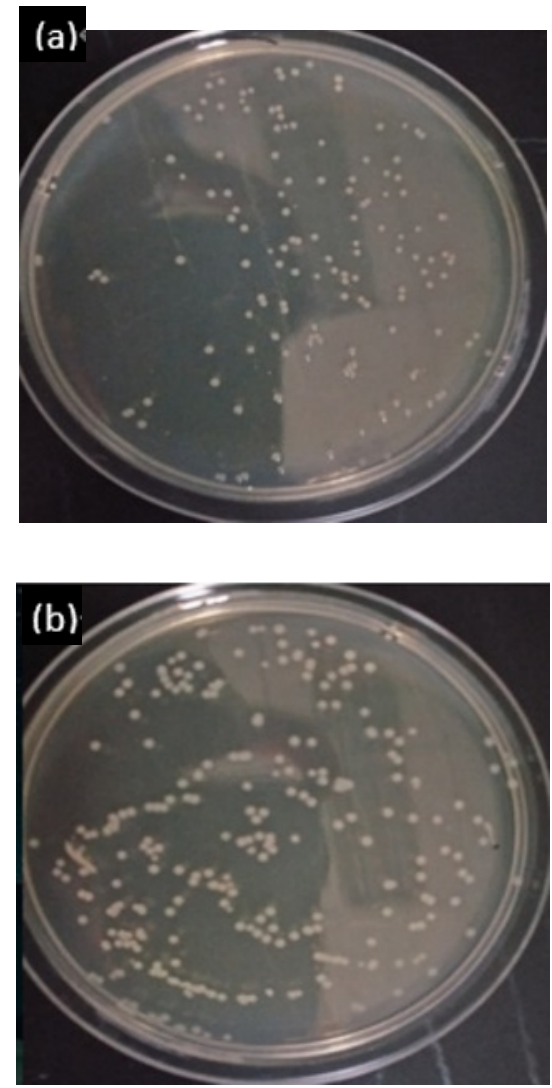

Fig. 4 The number of colonies treated $S$. aureus by (a) M-E-PL, (b) the blank control

Figure $3 \mathrm{a}$ shows the E. coli treated with M- $\varepsilon-\mathrm{PL}$, the colony number is 109 , and Figure $3 \mathrm{~b}$ shows the untreated E. coli, the colony number is 362 , and the sterilization 
rate can reach $70 \%$. It can be seen that M- $\varepsilon$-PL has obvious antibacterial effect on E. coli [9].

Figure $4 \mathrm{a}$ shows the $\mathrm{S}$. aureus treated with $\mathrm{M}-\varepsilon-\mathrm{PL}$, and the colony number is 149 . The colony number of the untreated $\mathrm{S}$. aureus is 268 (Figure 4b), and the sterilization rate can reach $70 \%$. It can be seen that M- $\varepsilon^{-}$ PL also has obvious antibacterial effect on S. aureus [10].

\subsection{SEM images of Pseudomonas fluorescens}
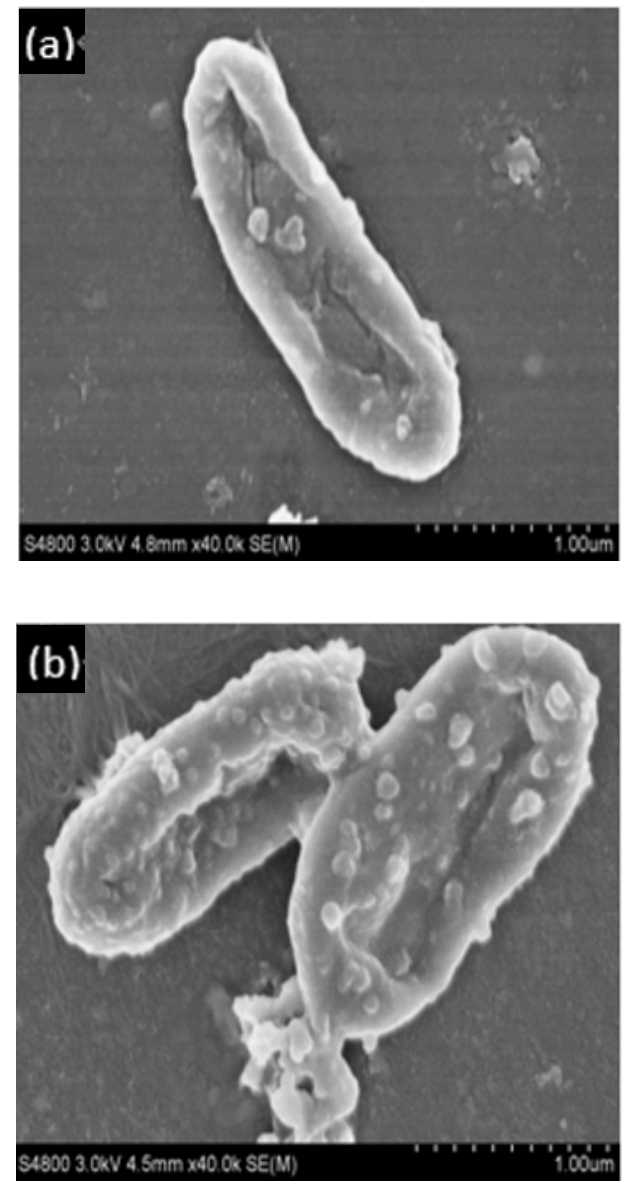

Fig. 5. Scanning electron micrograph of $P$. fluorescens without (a) and with (b) by $\mathbf{M}-\varepsilon-\mathbf{P L}$

Figure 5 shows the surface morphology of P. fluorescens after treatment with M- $\varepsilon$-PL has undergone significant changes. The cell wall membrane in the middle part of the bacterial body is broken and cracked, with obvious depressions. After analysis, it is believed that M- - -PL causes the protein in the cell membrane to be lost due to degradation, the example channel on the bacterial cell membrane is opened or lysed and damaged, the cell is ruptured, and the contents of the bacteria leak [11, 12], thereby achieving the antibacterial effect.

\section{Conclusions}

The M- - -PL synthesized by Ugi has mild reaction conditions, high reaction efficiency, low cost and simple operation. The antibacterial experiment proved that 20 $\mathrm{mg} / \mathrm{mL} \mathrm{M- \varepsilon -PL}$ can kill $70 \%$ of E. coli and $44 \%$ of $\mathrm{S}$. aureus. SEM can also show that it has a significant inhibitory effect on P. fluorescens, and the effect is better than general antibacterial agents, which have a good prospect in antibacterial research.

\section{Acknowledgements}

The project was supported by the Natural Science Foundation of Liaoning Province (2020-MS-289), the National Natural Science Foundation of China (Nos.21878023, U1608222), the Program for Distinguished Professor of Liaoning Province, the Liaoning Revitalization Talents Program (XLYC1807133), and the First-class Discipline Project of Liaoning Province.

\section{References}

[1] J. Liu, J. Xiao, F. Li, Y. Shi, D. Li, Q. Huang, Food Control, 91, 302-310 (2018)

[2] X. Liu, D. Li, K. Li, Y. Luo, Food Microbiol, 76, 257-266 (2018)

[3] L. Lin, X. Liao, D. Surendhiran, H. Cui, Food Packaging \& Shelf Life, 17, 134-141 (2018)

[4] Z. Song, F. Li, H. Guan, Y. Xu, D. Li, Food Control, 74, 34-44 (2016)

[5] X. Zhang, S. Wang, J. Liu, Z. Xie, S. Luan, C. Xiao, Y. Tao, X. Wang, ACS Macro Lett, 5, 1049-1054 (2016)

[6] E.W. Skjeflo, D. Christiansen, A. Landsem, J. Stenvik, T.E. Mollnes, Mol. Immunol, 112, 131-139 (2019)

[7] Claudiu T. Supuran, J. Enzyme Inhib. Med. Chem, 33, 485-95 (2018)

[8] U.G. Letuta, V.L. Berdinskiy, Russian Chemical Bulletin, 67, 1732-1737 (2018)

[9] D. Sharma, M. Gupta, S. Gupta, S. Jaglan, S.A. Mallick, Indian Journal of Agricultural Sciences, 89, 998-1004 (2019)

[10] A.S. Bazaid, S. Forbes, G.J. Humphreys, R.G. Ledder, R. O’Cualain, A.J. Mcbain, Sci. Rep, 8, 3876 (2018).

[11] U. Salma, S. Sultana, S.K. Saha, S.M. Ahmed, K. Nahar, Mymensingh Medical Journal: MMJ, 29, 248-253 (2020)

[12] J.E. Hyun, S.Y. Lee, Food Microbiol, 86, 33-43 (2020) 